\title{
Contemporary young motherhood: Experiences of hostility
}

\begin{tabular}{|r|l|}
\hline Journal: & Journal of Children's Services \\
\hline Manuscript ID & JCS-07-2016-0014.R3 \\
\hline Manuscript Type: & Research Paper \\
\hline Keywords: & $\begin{array}{l}\text { Young Women, Young Mothers, Hostility, Inferiorisation, stereotyping, } \\
\text { labelling }\end{array}$ \\
\hline \multicolumn{2}{|c}{} \\
\hline
\end{tabular}

\section{SCHOLARONE ${ }^{m}$ \\ Manuscripts}




\title{
Contemporary young motherhood: Experiences of hostility
}

\begin{abstract}
Purpose - The purpose of this paper is to illustrate the hostility many young women who are also mothers experience within their everyday lives.

Design/methodology/approach - The paper will draw on qualitative research, incorporating a narrative approach, to illustrate the hostility many young mothers experience on a daily basis. The research design included a focus group, semistructure interviews and participant observations.

Findings - The paper reports the findings of a study that explored the experiences of young women who are also mothers. The author presents the findings that indicate that many young women, who are also young mothers, experience hostile reactions and interactions as part of their everyday lives.

Research limitations / implications - the small sample size means that this study cannot be generalised, but it does contribute to the growing body of qualitative evidence in relation to young mothers.

Practical implications - The findings suggest that there needs to be more recognition and acknowledgement of the hostility young women experience. Such hostility could have deleterious consequences on the young women, their parenting ability and also on the children.

Originality / value - This paper documents the experiences of young women who are also mothers and how they experience hostility as a daily occurrence. The hostility ranged from verbal to non-verbal and how they felt they were being treated, inferences about their sexuality to stereotyping.
\end{abstract}

Keywords - young women, young mothers, hostility, stereotyping, labelling, inferiorisation

Paper type - Research paper 


\section{Contemporary young motherhood: Experiences of hostility}

\section{Introduction}

This paper explores the hostility that many young women, aged between 15 and 19 , who are also mothers, experience on a daily basis. The paper will begin by exploring the social construction of young motherhood and placing contemporary young motherhood into context. This will be followed by highlighting the findings from a study of young women who are also young mothers and how they endured derogatory verbal and non-verbal interactions in everyday places and spaces of daily life.

The paper focuses on one of the findings from the study undertaken in the north of England. The study focused on capturing young women's voices, their narratives and everyday experiences. This paper represents the voices of young mothers who are often inaccurately represented in the media, due to the political rhetoric. The focus is on their experiences of hostility. It will be argued that the hostility arises from the social construction and portrayal of young motherhood, but may also have historical legacies such as the unwed mother and normative femininity, which contributes to the devaluation and inferiorisation of young mothers. The paper concludes that such stigmatisation, discrimination and prejudice would not be tolerated in other sectors of society.

\section{Social construction of young motherhood}

It was during the 1980s and 1990s that a theoretical and political debate ensued in relation to Murray's (1990) underclass thesis. The 'underclass' refers predominately to young men who are living in poverty, are welfare dependent and long-term unemployed. They have an unwillingness to work, engage in criminal activity and have illegitimate children (Murray 1990). It would appear that the 'underclass' is an overarching term capturing different meanings depending upon the context in which it is being used. Daguerre (2006) suggests that 'there is clearly an overlap between the underclass, the illegitimacy and teenage pregnancy debates' (p. 70). The overlap is based on the generally held assumptions that teenage mothers are welfare dependent, unsuitable parents and have children who exhibit anti-social behaviour: 'the pervasiveness of stereotyping practices is such that young childbearing women are routinely scripted to become welfare dependent, inadequate mothers of unruly children who, in turn are destined to repeat the cycle' (Stapleton 2010, p. 10). However, there is little evidence to suggest that all young mothers are welfare dependent throughout their lifecourse trajectory.

As the underclass debate diminished a new phenomenon emerged in the UK. This was the introduction of the term 'Chav'. The chav, an acronym for "Council Housed 
And Violent," "Council Housed And Vile," and "Council Housed Associated Vermin" is usually associated with economic status and single young motherhood (Tyler 2008, p. 20). The typical characteristics of the female chav were frequently portrayed in the UK through the television programme 'Little Britain' and the character of 'Vicki Pollard' a young single mother. According to Hayward and Yar (2006) the underclass and the Chav are interconnected, but with the significant difference being that the underclass fails to engage in employment whereas the Chav is excluded from consumption. Consumption referring to appropriate societal norms and expectations, however for the Chav 'they consume in ways deemed 'vulgar' (ibid p. 14). The Chav is associated with working class women, familial disorder and dysfunction, fecund and excessive femininities (Skeggs 2005). Teenage motherhood is often associated with Chavs.

Nevertheless, the underclass thesis and Chav discourse fails to appreciate that many young girls are socialised to become mothers through intergenerational experiences: 'processes of gender differentiation and identity construction begin within families' (Morrow 2006, p. 94) and communities (Cater and Coleman 2006; Anwar and Stanistreet 2014; MacDonald and Marsh 2005). Based on their research with African Australian teenage mothers, Watts et al. (2015) argue that 'race, age, gender, migration experience, the family environment, socioeconomic status, educational background, and social networks prior to pregnancy contributed to a complex web of intersecting experiences that then shape teen pregnancy and early motherhood' (p. 8). A further contributing factor is the portrayal of femininity and female sexuality in children's literature and girls' magazines and through film and television where the focus is on heterosexual relationships (McRobbie 2000, Tinkler 1995). Such socialisation, experiences and portrayals have a huge impact on girls and young women with regards to expectations of normative femininity.

The Teenage Pregnancy Strategy, introduced by the Labour Government (19972010), has ended, however, the political agenda in relation to teenage motherhood continues with the present Government through the Public Health initiatives, the reduction of child poverty and early intervention via parenting classes (Rudoe 2014). Although not identified as a 'problem' it could be argued that there is the implicit notion that young mothers need to be monitored in relation to public health and child poverty outcomes. The Teenage Pregnancy Strategy was criticised from a feminist perspective because it was seen to remove the freedom of reproductive choice and sexual freedom (Hoggart 2003). The historical context of teenage pregnancy has its origins in America during the mid-1960s middle-class, single pregnant teenagers were secretly sent to relatives where they would either have their child or an abortion thus, 'the new phrase 'teenage pregnancy' went together with coming out ... In the early days it was a middle class affair' (Hacking 2002, p. 425). This is in contrast to contemporary society where the term 'teenage pregnancy' is generally associated with the traditional working classes and poverty (ibid). 


\section{Contemporary young motherhood}

The tendency to pathologise and problematise teenage mothers is well documented in the United Kingdom (Arai 2009; Brown et al. 2011; Duncan et al. 2010) and internationally (Easterbrooks et al. 2011; Gyesaw and Ankomah 2013; Hunt et al. 2011; Watts et al. 2015). Contemporary young motherhood is generally identified as 'teenage pregnancy', and 'teenage mothers' and is depicted as a 'health problem' (Clift-Mathews 2010) and 'social problem' (Department for Children, Schools and Families and Department of Health 2010; Social Exclusion Unit 1999). They are represented as a 'risk' to society and to themselves (McDermott and Graham 2005). However, there have been a number of significant challenges to this dominant narrative (Arai 2009; Duncan 2007; Duncan et al. 2010; Lawlor and Shaw 2002). The 'problemisation' discourse focuses on teenage pregnancy and teenage motherhood; however, it does not recognise that this is only part of the young women's identities. These young women are situated within multiple-identities, many of which are complex and intertwined within contemporary family structures and some may have experienced the care system. The problematisation thesis focuses upon, and emphasises, the social determinants of the young women such as socio-economic status and education in addition to intersectional factors, for example their age, class and ethnicity. However, there is little consideration given to the young women themselves other than the notion that they lack formal educational qualifications, are from and likely to remain, single parent families and whose children exhibit antisocial behaviour. Nonetheless, these young women are experiencing and navigating life as young women while at the same time developing their identity that incorporates motherhood.

Despite the young women's newly acquired status as mothers, they are problematised and vilified because of choosing a different path from their middle class peers (Wilson and Huntington 2005). They are regarded as being outside the prevailing cultural norms of motherhood and therefore, considered to be 'unsuitable mothers' (McDermott and Graham 2005, p. 70). McDermott and Graham (2005) identify several attributes associated with young motherhood including welfare dependency and an increased risk of poverty in addition to being constructed as a "risk' within society and a 'risk' to society ... because of their age and class' (p.60). Stereotypically, young motherhood is associated with young women from working class families. The notion of risk is further escalated by Frances (2010) who reports that if teenage pregnancy does not remain a prioritisation for central and local government it will become a 'major risk' (p. 3).

In contrast, the notion of risk is also illustrated by Macvarish (2010) however this is the risk to the young mothers in relation to the construction of young motherhood as a problem. Such risks consist of the government's rhetoric and policies, professional's discourse and individual's mannerisms and exchanges all of which promote the problemisation and negativity so often associated with young 
motherhood and for many young mothers resulting in hostility towards them and stigmatisation (Arai 2009, Duncan 2007, Yardley 2008). For example, Arai (2009) identified that 'nearly all the women said they had experienced hostility towards them' (p. 177).

\section{Research design}

The study was undertaken in a city and two towns in northern England and aimed to explore the experiences of young women who were aged between 15 and 19 years and were also mothers. The city and towns where the research was conducted have experienced, and continue to undergo, significant social and economic changes following the decline of heavy industry. They have high unemployment rates, areas of disadvantage and deprivation and conception rates for the under twenties are above the national average for England however the figures are declining (PotterCollins and Beaumont 2012).

A qualitative research study was undertaken using a narrative approach (Andrews et al. 2013). As described by Riessman and Quinney (2005) 'narrative inquiry in the human sciences is a $20^{\text {th }}$ century development; the field has 'realist', 'postmodern' and constructionist strands (p. 393). Purposive sampling (Singleton and Straits 2005) was used and participants accessed through their attendance at:

- four support projects;

- three hostels;

- one Education Centre.

Access to various research sites was negotiated with project managers. All of the projects, hostels, and the Education Centre provided support and education related opportunities to young women who were pregnant or young mothers who lived in the city and towns irrespective of socio-economic background. Meetings with managers provided the opportunity to discuss the research and subsequently meet other staff members. These meetings were followed by meeting the young women at each of the sites and discussing the purpose of the research. Participation was voluntary and based on informed consent. In the interests of confidentiality, pseudonyms are used throughout the paper. All of the young women were between 15 and 19 years of age. Each participant was provided with an information sheet. Ethical approval was gained from the University Research Ethics Committee.

A total of fifty-six young women participated in the study including:

- twelve young women who were pregnant;

- forty-two young women who were mothers;

- two young mothers who were pregnant with their second child. 
At the Education Centre there were:

- twelve participant observation sessions - these sessions were conducted at the Education Centre over the lunchtime period and were 45 minutes in duration;

- six semi-structured interviews;

- one focus group (one hour duration) - six participants attended.

Participant observations were also undertaken at:

- one mother and toddler session - support project;

- one activity session - support project;

- three participation observation sessions - one hostel.

Semi-structured interviews were also undertaken at:

- two semi-structured interviews;

- one semi-structured interview - support project;

- two semi-structured interviews - support project;

- three semi-structured interviews - support project;

- three semi-structured interviews - one hostel;

- one semi-structured interview - one hostel;

In total:

- one focus group was conducted.

- thirty-six hours of participant observations were carried out. Written recordings were made during observations and afterwards. This allowed for data to be gathered across a range of dimensions.

- eighteen semi-structured interviews were carried out.

The interviews and focus group were audio recorded. These recordings were transcribed verbatim by the researcher. A thematic analysis of the narratives and fieldnotes was conducted manually and through a narrative network analysis (Attride-Stirling 2001). Once the interviews were transcribed two copies were made so that one could be cut into 'chunks' of text. The researcher then began collating the different chunks which formed the categories as they emerged from the process. These categories were continually re-calibrated as further transcriptions were completed. The fieldnotes were analysed using a similar process. Both were then compared until it was possible to identify overarching themes and sub-categories. The young women's narratives were rich in descriptive detail and have been retained within this paper which draws directly on the words and terminology used by them to describe their experiences. 


\section{Hostility towards young mothers}

The data collection methods enabled the researcher to gather data from a variety of sources that provided rich narrative accounts about the hostility the young women were subjected to on a daily basis. They gave graphic accounts of being shouted at, sworn at, and how name calling was a frequent occurrence. The young women spoke of the language used, the manner in which it was conveyed along with the name calling which was defamatory, disapproving and distressing. The hostility usually began during pregnancy and continued following the birth of the child. It is important to note that some of the following accounts are substantial as these situate the young women's experiences into the context of daily life, while at the same time illuminating the emotionality attached to the experiences. These narratives demonstrate how the hostility had previously, or continued to permeate all aspects of the young women's lives.

\section{Being treated funny}

The young women shared their experiences of health appointments, being in hospital and particularly the way professionals worked with them. They discussed how some midwives were 'funny' with them. Through explorative dialogue it was established that 'funny' meant they felt they were treated with disrespect and in a patronising manner. The lack of, or inappropriate, discourse in addition to not being listened to and ignored were the most significant factors reported. The young women's experiences included how midwives would talk to their parent(s) and/or their parent's partner as if they were not there. The young women felt that they had become invisible. Louise's (16 year old) account illustrates how she felt:

We get treated like crap, so unfairly.

Molly (16 years of age) observed that she was:

Treated like a two year old when giving birth.

Louise and Molly's assertions were echoed by many of the young women who described similar sentiments and had comparable experiences from health and social care professionals.

When sharing their experiences of non-verbal and verbal actions and interactions the young women described how the 'looks' and 'intense stares' made them feel uncomfortable, intimidated and distressed. They reported that 'looks' and 'comments' evoked emotions of anger, frustration and at times intimidation. They said how they endured such experiences when travelling to and from school, college, or when shopping alone, or with friends or family members. No particular time, space or location was identified, nor specified, for these occurrences and therefore the young women could not take steps to avoid the situations. These incidents were 
spontaneous and often occurred several times a day. The impact of the verbal and non-verbal mannerisms resulted in many of the young women feeling disempowered while a significant number felt that they had become less confident. Additionally, many described how they felt both physically and mentally anxious and emotionally upset and frustrated. They spoke about 'feeling sick' and distraught.

The young women reported that there could be no differentiation made between gender, age or ethnicity of the people responsible for the hostility. However, when sharing their experiences the young women only described, and gave examples of the behaviour from other women. These women were of all ages and ethnic backgrounds. They said that people looked at them disparagingly. This was highlighted in the following two accounts:

They [people] just look down on you. (Debbie 17 years old)

When she, [referring to her daughter] was first born I got dirty looks. (Amy 17 years old)

Debbie and Amy's comments were similar to other young women's experiences. During the focus group Sam (16 year old) said that:

It's like we're dirty or something, like we've done something wrong.

The young women were asked to describe the 'look' and what they meant by 'looking down', 'dirty looks' and the 'intense stare'. Whether during an interview or group discussion the young women provided similar adjectives to describe the non-verbal gestures. They demonstrated these gestures through their facial expressions and body language. These included a wide eyed gaze, an intense stare, sometimes frowning, sometimes the lips curled slightly, but certainly not smiling and always a look of disgust and disapproval. Sometimes the looks were from a distance, or a passing stare, while other times individuals 'will come right up to you'. The manner to which feelings were articulated varied. Some of the mothers were more emotional than others, for example common emotions that were exhibited included anger, upset and defensiveness. Whereas others questioned why people looked at them in such a way and why people were making judgements about them. The 'why' was usually followed by 'I haven't done anything wrong'. Sometimes the look was accompanied with barely audible comments:

You get the look and when people walk past they'll murmur things, say things under their breath. (Debbie 17 years old)

This was also reported by Adele who said that she frequently experienced: 
Mutterings and people saying things under their breath, usually calling you names and things. (Adele 17 years old)

Harriett (16 year old) reported that she took pride in her appearance and how appearance was important for herself and her daughter reporting that:

People always look at you.

Elaborating further, Harriett explained that people looked at her as though she could not look after herself and certainly was not be able to care for her child. She concluded that there was an ever-present feeling that people were constantly judging her. Therefore for her, ensuring that she was presentable demonstrated that she was capable of being a good mother.

Bethany (16 years old) talked about how people had said to her 'you have wasted your life'. She explained how, in her opinion, people made judgements about the lives and the experiences of young mothers without knowing anything about them, their situation or circumstances. This was consistent with another group discussion where mothers reflected on their experiences of being called names and how people constantly made assumptions about their lives and lifestyles.

\section{Going out: violence and aggression}

All of the young women shared experiences of verbal interactions and non-verbal gestures. The following accounts characterise the experiences reported by the young women. The looks and comments were reported as being subjective and personal. An example of such was Lilly (16 years old) who described:

When I was pregnant walking down the street people would call me names, slut, slag, f...ing bitch, and swear at me.

Roxie (18 years of age) reported that:

When I got pregnant at sixteen all I got was you're a slag for having a kid at a young age.

And Courtney (16 years old) explained:

I get called names and shouted at all the time; people think cos you've got a child and look young they can have a go at you.

These assertions were consistent with the other young women's narratives. Each narrative was similar in content as they described how the 'looks' made them feel self-conscious and uneasy. One young woman, Annabel (16 years old) reflected on 
her experiences of being attacked. She explained that she was walking near to where she lived when a woman began shouting at her and calling her names. She estimated that the woman was in her forties and lived in the same geographical area, but was a stranger. Annabel reflected on how she initially ignored the woman, but felt distressed. The name calling referred to her age, an assumption being made by the woman, however, Annabel said that she was fifteen at the time, and 'heavily pregnant'. Ignoring the comments provoked further verbal abuse followed by a physical attack. Annabel said that she had to retaliate, but also disclosed that she was then subsequently charged for assault while the individual was not.

The young women shared the verbal and non-verbal behaviour that they experienced with expressive clarity. They reiterated the nuances and milieu of each occurrence. The following exemplifies the emotions of many of the young women who were confronted by verbal interactions. The following fieldnotes were recorded during and after attendance at a drop-in session and provide a sense of the tension, anger and frustration felt by Georgina (17 years old).

While talking to some mothers at the Drop-in, I observed another mother walking into the room. The walk was abrupt she was talking loudly almost shouting. A project worker went to see what the problem was. Following my discussion, I went to the table where the distressed mother was, introduced myself and asked if I may sit down. Some mothers recognised me from the introductory session the previous week. They were talking about the stigma they feel and receive on a daily basis. The mother who had arrived angry and distressed had been subjected to derogatory comments during the journey to the Drop-in. During the recounting of the event my observations were of someone who was angry but also upset and emotional. I thought about the potential impact this may have on confidence, self-esteem and parenting.

During the next segment the descriptive language used by Georgina showed how this was not an isolated incident.

During the discussion the mother's tone increased along with hand movements and non-verbal communication and colourful and descriptive language. One mother informed me that it was nineteen year olds who 'look down on them' while another mother stood up and adjusted her right hand to form a ' $v$ ' shape and thus could demonstrate how these 'girls' hold their handbags. She mimicked a walking motion, gently swaying her hips from left to right, raising her eyebrows and turning her nose up to illustrate the typical behaviour they encounter 'some girls call us names, some just look at us, 'designer handbags, clothes and all made up' - 'who do they think they are'. The air was tense. Five mothers each sharing their own experiences to contribute to the overall picture. 
In the final segment, Georgina stated how she would have addressed the matter prior to the birth of her child. This segment also illustrates how the mother's demeanour changed when she started talking about her child.

The mother who had arrived angrily and upset stated that 'I felt like smacking her' and went on say 'before I had her [referring to her daughter] I would have done'. The remark illustrated the anger this young woman was feeling but also demonstrated how she had changed her behaviour and the way she addressed situations differently 'I can't be bothered, I need to think of, [name of child] she comes first'. She did not divulge what had been said or the actions she had been subjected to and I did not want to exacerbate the situation or cause further distress thus did not enquire further. Interestingly, the young women's discourse, and facial expressions changed almost instantaneously when they talked about their babies. There was a calm, peaceful, serenity. It was amazing to observe such a change of atmosphere and suddenly quietly spoken, smiling mothers.

The above highlights the anger and frustration that was clearly demonstrated when Georgina said, 'I felt like smacking her' and shows how she had changed since the birth of her baby through the comment in relation to placing her baby first. The feelings of intensity demonstrated by Georgina reverberated round the table as each young woman shared their own experiences of similar situations with a variance of how they might have reacted. A range of different environments, where these experiences occurred, included shopping centres, town centres, supermarkets, when on public transport and in other public spaces and places. The words resonated with resounding similarity.

\section{Sexuality}

The following accounts provide an insight into how the young women felt in relation to the non-verbal and verbal behaviour:

Looking younger than what I really am people look at me and think she's slept with people at like thirteen, fourteen, so she's a slag. (Debbie 17 years old)

Through Debbie's account the interconnectedness between how an individual looks, for example looking younger than their age, the presumed sexual activity, for example that the child is theirs, and how people consider what the appropriate age is to engage in sexual behaviour is illustrated through the account. Whereas Liz refers to being young and having a partner:

When you have a kid at a young age it's not the fact that she's been with a partner three years, it's the "oorr she's opened her legs she's a slag", this and 
that and the other, that's typical thing you usually get it off anyone. (Liz 18 years old)

The significance of this account is Liz's own analysis of the importance of long-term relationships and their self esteem, which implies an acceptance of the general attitudes in relation to sexuality and partners. Similar to Debbie, Liz also refers to the name calling she experienced. Adele shared her feelings about assumed sexual promiscuity, but similar to Liz placed importance on long-term relationships:

I get funny looks, called a slag, a slut, and people make assumptions when you are a young mother that you've slept around, go with lots of lads but I'm still with my boyfriend [the baby's father]. (Adele 17 years old)

These accounts demonstrate how the young women believed that they were labelled for differing reasons. However, when analysed in the context of young motherhood assumed age was a common factor along with reference to sexual activity in addition to partners and intimate relationships. These three significant accounts typify the experiences of all the young women whose narratives resonated with similarity. Liz articulates eloquently:

Because everyone automatically thinks that you've jumped into bed with someone, didn't use owt [contraceptives] and there you go you've got a kid, it's no one looks at the circumstances behind it, so yea they automatically think you're on your own, this has happened, that has happened, and that's that it's either black or white there's no in between, it happened or it didn't sort of thing. (Liz 18 years old)

Liz's account suggests a monochromic explanation as to why she thought people looked and made such comments about young mothers. Within her account, she was rationalising why people were making assumptions and judgements about young women and again there were elements within this account that had been identified previously for example age, assumed sexual promiscuity and the notion of single motherhood. In the following account, Kitty (16 years old) shared her thoughts, and although these were similar to the above accounts and the notion of sleeping around, she also highlighted the difference between having a child and not having a child.

There were somebody, same age as me, and she slept with about a million times more people than me, l've only been with one person which is my baby's dad, and she tried to say that I was a slapper and all this and that like I said "that's rich coming from you, you don't know how to pull your knickers up", like people think they can call you a slag cos you've got a baby but I've only been with one person and I'm still with him and they've been with like one hundred people. 
The above accounts indicate that the derogatory labels attached to young mothers are because of their assumed age and sexual activity. There is no consideration to the young women's relationship with their partner, their personal circumstances or experiences.

\section{Stereotypes}

During a parent and toddler group Nancy (18 years old) shared her experiences of visiting an indoor garden centre with her daughter. She explained how she used the centre as an educational experience for her daughter. This included exploring the colour, shape and size of plants and opportunities for language development. Additionally, the activities provided by the centre facilitated mother and child interactions.

When discussing these visits and especially when talking about her child, Nancy's facial expression gleamed and appeared very excited. She spoke with elation and pride when sharing her experiences. However, during a recent visit to the centre a woman with her partner and child, made a derogatory comment to her about being a young single mother. The comment made reference to her age and perceived relationship status. Once again demonstrating how assumptions are often made. Nancy reported that she felt that she had to say something, and thus replied:

You're lucky you're with your partner, but mine's at work today.

The inference that Nancy was a 'young mother' and 'single' was inaccurate and a presumption. The comment made was negative and referred to her age and relationship status, but did not consider the recreational or educational value of the visit. This is significant because it illustrates the one dimensional construct of young motherhood which is negative, but fails to acknowledge positive parenting, the mother / child interaction and the possibility that young mothers may also have partners, who are employed. This experience resonated with other young mothers, with partners, who reported how there is a general assumption that all young mothers are single parents.

When the young women were sharing their experiences of this hostility they reported that initially, during the pregnancy and following the birth it was felt more intensely. However, over time they became more accustomed to it although there were some occasions when it was impossible to ignore the hostility. The young womens' assertions that they became accustomed to the hostility would suggest that the behaviour had become normalised and accepted. The young women reflected on how this hostility towards them was perceived as a reflection of their ability to be a mother. 
The mothers reflected upon the comments made to them and in particular those that questioned their ability to look after their child. They reported that the individuals making the comments had no knowledge of their previous experiences, situation or circumstances, which often included looking after younger siblings and other family relations. The account from Adele (17 years old) was typical from the majority of the young women:

Being the oldest, I took care of my brothers and sisters since I was about seven.

However, it would appear that the individuals, who were responsible for the hostility towards the young mothers, failed to show consideration of the young woman's background, situation and circumstances. Instead they made assumptions and judgements. This was highlighted by Courtney (16 years old) when she shared her experiences of being shouted at by an older woman during the latter stages of her pregnancy:

The woman had no idea of what I've been through, people like that make me sick.

Courtney's account illustrates how the comments are distressing, insensitive but again demonstrates no appreciation of the young woman's situation and circumstances. Courtney did not elaborate further, but this highlighted how people did not demonstrate self-awareness, compassion or the potential anguish they were causing. The young women were adamant that age was irrelevant with regards to looking after children. They referred to their previous experiences, but also their energy when playing with their children. All of the young women felt that they were able and capable of being good mothers and were more than able to look after their children.

When the young women were reflecting on their experiences of people looking at them and making comments, they reported that initially, during pregnancy and following the birth it appeared to be more intense, but how this behaviour became accustomed to although there were some occasions when it was impossible to ignore. The following account was an experience Liz (18 years old) shared during an interview.

You have looks and stuff like that you're bound to get funny looks but it's better to walk away. It's like I remember I was stood in a queue at [name of newsagents] looking at chocolate that sort of stuff thinking what can I treat myself to and this woman randomly went to shove in front of me. So I said "don't worry about me love" it weren't as if I was waiting or owt [anything] you know what I mean obviously I had my baby in the pram and this woman didn't hear me and her daughter was stood behind me and she walked up mouthing 
Liz's account illustrates how the hostile behaviour becomes normalised and acceptable 'you're bound to get funny looks', as if the whole notion of being in a shop with your own child is an unacceptable or an unknown phenomenon. Liz also highlights how she was referred to as a 'typical teenage parent', which raises the question of where does the image of a stereotypical teenage parent arise? What does a 'teenage parent' look like? And, are they all the same? The problematisation discourse of young mothers by the government and media would suggest that they are a homogenous group and thus presents an inaccurate portrayal of young motherhood.

\section{Discussion}

The dominant discourse identifies young women who are also mothers as a problem. These young women are often associated with welfare dependency, lacking formal educational qualifications and as single parents. However, the dominant discourse fails to appreciate the hostility these young women experience on a daily basis. The findings indicate that hostility would appear to be founded on assumptions, stereotypes and perceptions of young women who have children in their teenage years. Despite the dominant discourse, the hostility appears to transcend class and the rhetoric by the government, media and the general public that young mothers are from single parent households, welfare dependent, and lack formal educational qualifications. Young women with children are placed within a homogenous group and as such experience similar experiences in relation to being judged, stereotyped, labelled and problemitised. Nevertheless, the contextualisation of young mothers as a problem is not a new phenomenon and may have historical connotations (Bainbridge 2009, Cherrington and Breheny 2005). It is from these historical legacies that the vilification and problematisation of young motherhood may exist, which are particularly reminiscent of the unwed mother who does not meet societal norms and expectations and who have, throughout history, been criticised and problematised (Wilson and Huntington 2005). Thus, having a child out of wedlock is a moral issue, in need of control, and a burden on society:

From the late sixteenth century in England, the unmarried 'Lewd Women' who produced bastard children became 'typical' of what was morally wrong with society ... The 'lewd' woman was reprehensible both in herself, and as the 'stand-in' for early modern social evil (Cregan 2001, p.126). 
Cregan illustrates how the unwed mother was regarded as both morally wrong and evil. The unwed woman was blamed for the ills of society. The reference to 'unmarried' and 'unwed' mothers is also pertinent because it 'underscores the devaluation of single mothers and shows that their perceived offence lies partly in a violation of marital norms' (Schur 1984, p. 63). Furthermore, following the 1980s political rhetoric and the notion of young single mothers as the 'national evil' (Skeggs 2005 , p. 965) they continue to be regarded as a problem. When contextualising these historical legacies into contemporary society, the current discourse relates to single parent households who are frequently blamed for many of the social problems that exist today, although 'single parent' usually insinuates 'bad mothering' (France et al. 2012, p. 121).The discursive dialogue surrounding the problemisation of young motherhood supports the notion of the historical contexts, which could relate to both the contextualisation of the unwed mother and functionalist perspective of the nuclear family. Through the historical lens the prejudice, stereotyping, labelling and hostility is legitimised.

Driscoll (2002) refers to, the transition from 'girl' to 'woman' the latter including marriage and having children, in that order complies with the normative femininity and the traditional societal and canonical expectations of a woman. Thus the young woman establishes her career, delays motherhood and follows the expectations of nominative femininity (Harris 2004). Conversely, the young women who do not proceed through this contemporary life course trajectory are classed as 'at risk' because they either disengage, or do not continue, in formal education and do not have a planned professional career (Harris 2004). They have a child. These young women, still in their teenage years, are referred to as 'teenage mothers'. These are perceived as a 'symbol of social decline, social failure or social backwardness' (Macvarish 2010, p. 2). Clearly the implicit discourse remains focused upon the heterosexual relationship and the notion of marriage: 'feminine adolescence as growing-up is measured by the womanly roles of motherhood, feminine sexuality, and wifedom, which proscribe end points to that process' (Driscoll 2002, p. 57). Anything other than is 'perceived' as deviant.

Adam (1978) associates deviance with the inferiorisation of individuals and subsequently stigmatisation. Thornicroft et al. (2007) link stigma with ignorance, prejudice and discrimination, while Link and Phelan (2006) illustrate the intersectionality of labelling, stereotyping, identifying individuals as undesirable, polarising and discriminating individuals along with exercising power with stigmatisation. Drawing on the work of Thornicroft et al. and Link and Phelan the conceptualisation of stigma is evident in the language used in relation to young women who are mothers. They are described as a 'problem', as a 'risk to society' and previously associated with the 'underclass' and more recently 'Chav'. Reference to married, unmarried, along with labels such as underclass and Chav, in addition to 
the problematising and identifying them as a risk, polarise people and thus suggests that some individuals are, as Adam (1978) proposes, inferior.

Individuals who initiate such hostility have their own interpretation, attach meanings, and have their own ideological beliefs in relation to young motherhood. However, the consequences of such are the assumptions they make about the lives of these young women. It is evident that Adam's (1978) notion of inferiorisation is illustrated through the actions and interactions towards young women who are also mothers. This inferiorisation in the form of labelling and stereotyping is resulting in the disparaging and denigration of young women who are mothers. The young mothers were, at times, intimidated, but also angry and distressed by the 'looks', 'stares' and 'verbal abuse'. These experiences of hostility demonstrate how dominant 'macro' narratives, the dominant discourse, impacts on the everyday 'micro' experiences of young people.

\section{Conclusion}

The young women's narratives indicated that they were subjected to hostile reactions on a day-to-day basis. These reactions have the capacity to provoke a myriad of emotions including intimidation, distress, but also confusion, frustration and anger. The young women did not understand why they were being treated in such a manner. They felt that they had not done anything wrong and that the looks, intense stares and verbal comments were an assault on them. Many of the mothers thought that health and social care professionals were disrespectful towards them. The majority of the young women had observed that the midwives had generally directed their conversations towards their mothers or fathers and their partners and not directly at them. Professionals undermining young women who were pregnant, or who had children, was a frequent discussional topic. Existing research (CliftMathews 2010) suggests that young pregnant women are less likely to engage in health related services; when listening to the experiences of the young women in the current study it is not surprising that they did not engage in services. The narratives indicated disparaging comments, insensitivity, disrespect, and a lack of consideration of the young women's circumstances.

Reflecting upon their experiences, the young women said that the hostility was more prominent during pregnancy and immediately following the birth. They became accustomed to this behaviour, which formed part of everyday life. This normalisation of such hostile behaviour does not excuse it, but demonstrates how the young women are situated within institutional and societal discrimination, stigmatisation and have to tolerate prejudicial attitudes. This includes when they are with professionals, within the public gaze, and confronted by a discourse and media representation that constructs and portrays them as a problem when they are doing what so many young women have done previously. It is unlikely that such hostility would be 
accepted in any other population of society where equality, diversity and individualisation are promoted.

Contextualising young motherhood as a problem, in addition to the negative projected lifecourse trajectory and a whole range of other labels, positions young mothers as deviant and thus potentially criminalising their behaviour. The notion that all young mothers are a risk to both themselves and to society is also flawed. As Macvarish (2010) suggests the risk is to the young women and this risk relates to the construction and discourse of young motherhood. However, such connotations are not new, pregnant young women and young mothers, have been ascribed to certain social groups, such as the underclass and have been branded for example Chavs. The rationale for such labels is that they are not accepted, and to some extent within the expected cultural norm of marriage first, followed by childbirth, but this does not take into consideration the changing nature of social structures and contemporary constructs of the family. However, it does have undertones of a historical context, for example the unwed mother, the normative femininity and gender ascribed roles.

The cumulative effect of such labelling, government policies and rhetoric and media representation is potentially placing the young women and their children at considerable risk. Risk is multi-dimensional and the detrimental consequences of such continuous and subsequent acceptance of negativity could have detrimental consequences in relation to parenting ability, child development in addition to the physical threat. However the ideology of young mothers as a problem and deviant also situates them as inferior, and thus contributes towards the marginalisation and stigmatisation of young motherhood. Nevertheless, young women who are mothers are caught up in a vortex of political rhetoric to which the media then sensationalises the discourse and as a result portrays young mothers as escalating to epidemic proportions, unemployed, welfare benefit dependent, a risk to society, unfit mothers and acquiring social housing. The interplay between the structural factors and the socio-historical context of unwed mothers and the contemporary portrayal of single mothers compounds the negativity further. Both the government and the media fail to differentiate between the young woman's age and/or family situation or circumstances. This issue needs addressing. Hostility towards young mothers needs addressing through the raising awareness of unacceptable behaviour, the potential impact on health and well-being, including self-esteem and inferiorisation of young mothers. These areas require further research that also includes the potential longterm impact on young women, whether these areas impact on their parenting ability, in addition to the possible risk factors the young women and their children may be exposed to. Furthermore, if, as suggested, the historical legacies are a significant factor along with the stereotypical perspective of normative femininity and traditional family structures, then these need to be challenged and young mothers need to be placed within the context of contemporary family structures and valued as individuals. 


\section{References}

Adam, B. D. (1978) The Survival of Domination: Inferiorization and Everyday Life, New York: Elsevier.

Andrews, M., Squire, C., and Tamboukou, M.(2013) Doing Narrative Research(Second Edition), London: Sage Publishing.

Anwar, E. and Stanistreet, D. (2014)'It has not Ruined my Life; It has Made my Life Better': A Qualitative Investigation of the Experiences and Future Aspirations of Young Mothers from the North West of England, Journal of Public Health, 37(2): 269-276.

Arai, L. (2009) Teenage Pregnancy: The Making and Unmaking of a Problem, Bristol: The Policy Press.

Attride-Stirling, J. (2001) Thematic Networks: An Analytic Tool for Qualitative Research, Qualitative Research, 1(3): 385-405.

Bainbridge, D. (2009) Teenagers: A Natural History, London: Portobello.

Brown, G., Brady, G., and Letherby, G. (2011) Young Mothers' Experiences of Power Control and Violence within Intimate and Familial Relationships, Child Care in Practice, 17(4): 359-374.

Cater, L. and Coleman, S. (2006) 'Planned' Teenage Pregnancy: Perspectives of Young Parents from Disadvantaged Backgrounds, York: Joseph Rowntree Foundation.

Cherrington, J. and Breheny, M. (2005) Politicizing Dominant Discursive Constructions about Teenage Pregnancy: Re-Locating the Social: Health: An Interdisciplinary Journal for the Social Study of Health, Illness and Medicine, 9(1): 89-111.

Clift-Mathews, V. (2010) Outcomes for Older and Younger Mothers, British Journal of Midwifery, June 2010.

Cregan, K. (2001) She was Convicted and Condemned, Social Semiotics, 11(2): 125-137.

Daguerre, A. (2006) Teenage Pregnancy and Parenthood in England, in A. Daguerre and C. Nativel (Editors) When Children Become Parents: Welfare State Response to Teenage Pregnancy, Bristol: The Policy Press. 
Department of Education and Skills and Department of Health (2007) Teenage Pregnancy Research Programme Research Briefing: Teenage Parenthood and Social Exclusion: A Multi-Method Study, London: The Stationary Office.

Driscoll, C. (2002) Girls: Feminine Adolescence in Popular Culture and Cultural Theory, New York: Columbia University Press.

Duncan, S. (2007) What's the Problem with Teenage Parents? And What's the Problem with Policy?, Critical Social Policy, 27(3): 307-334.

Duncan, S., Alexander, C. and Edwards, R. (2010) What's the Problem with Teenage Parents?, London: Tufnell Press.

Easterbrooks, A., Chaudhuni, H. J., Barlett, D. J., Copeman, A. (2011) Resilience in Parenting among Young Mothers: Family and Ecological Risks and Opportunities, Children and Youth Service Review, 33: 42-50.

France, A. (2007) Understanding Youth in Late Modernity, Maidenhead: Open University Press.

Gyesaw, K. Y. N. and Ankomah, A. (2013) Experiences of Pregnancy and Motherhood among Teenage Mothers in a Suburb of Acceu, Ghana: A Qualitative Study, International Journal of Women's Health, 5: 773-780.

Hacking, I. (2002) What is Social Construction? The Teenage Pregnancy Example, in G. Delanty and P. Strydon (Editors) (2003) Philosophies of Social Science: The Classic and Contemporary Readings, Maidenhead: Open University Press.

Harris, A. (2004) Future Girl: Young Women in the Twenty-First Century, London: Routledge.

Hayward, K. and Yar, M. (2006) The 'Chav' Phenomenon: Consumption, Media and the Construction of a New Underclass, Crime, Media, Culture, 2(1): 9-28.

Hoggart, L. (2003) Teenage pregnancy: the government's dilemma, Capital and Class, 27(1): 145-165.

Hunt, G., Moloney, M., Joe-Laidler, K. and McKenzie, K. (2011) Young Mother (in the) Hood: Gang Girls' Negotiation of New Identities, Journal of Youth Studies, 14:(1): 1-19.

Lawlor, D. A. and Shaw, M. (2002) Too Much Too Young? Teenage Pregnancy is not a Public Health Problem, International Journal of Epidemiology, 31: 552-554. 
Link, B. G. and Phelan, J. C. (2006) Stigma and its Public Health Implications, The Lancet, 367: 528-529.

MacDonald, R. and Marsh, J. (2005) Disconnected Youth: Growing Up in Britain's Poor Neighbourhoods, Basingstoke: Palgrave Macmillan.

Macvarish, J. (2010) The Effect of 'Risk Thinking' on the Contemporary Construction of Teenage Motherhood, Health, Risk and Society, 12(4): 313-322.

McDermott, E. and Graham, H. (2005) Resilient Young Mothering: Social Inequalities, Late Modernity and the 'Problem' of 'Teenage Motherhood', Journal of Youth Studies, 8(1): 59-79.

McRobbie, A. (2000) Feminism and Youth Culture (Second Edition), Basingstoke: Macmillan Press.

Morrow, V. (2006) Understanding Gender Differences in Context: Implications for Young Children's Everyday Lives, Children and Society, 20: 92-104.

Murray, C. (1990) Underclass, in C. Murray (Editor), The Emerging British Underclass, London: The IEA Health and Welfare Unit.

Potter-Collins, A. and Beaumont, J. (2012) Measuring National Well-being Measuring Young People's Well-being, 2012, London: Office for National Statistics.

Riessman, C. K. and Quinney, L. (2005) Narrative in Social Work: A Critical Review, Qualitative Social Work 4(4): 391-412.

Rudoe, N. (2014) Becoming a Young Mother: Teenage Pregnancy and Parenting Policy, Critical Social Policy, 34(3): 293 - 311.

Schur, E. M. (1984) Labelling Women Deviant, Gender, Stigma, and Social Control, New York: McGraw-hill Publishing Company.

Singleton, R. A. and Straits, B. C. (2005) Approaches to Social Research (Forth Edition), Oxford: Oxford University Press.

Skeggs, B.(2005) The Making of Class and Gender through Visualising Moral Subject Formation, Sociology, 39(5): 965-092.

Social Exclusion Unit (1999) Teenage Pregnancy, London: The Stationary Office.

Stapleton, H. (2010) Surviving Teenage Motherhood: Myths and Realities, Basingstoke: Palgrave Macmillan. 
Thornicroft, G., Rose, D., Kassam, A. and Sartorius, N. (2007) Stigma: Ignorance, Prejudice or Discrimination?, The British Journal of Psychiatry, 190: 192-193.

Tinkler, P. (1995) Constructing Girlhood: Popular Magazines for Girls Growing up in England 1920 - 1950, London: Taylor and Francis.

Tyler, I. (2008) “Chav Mum Chav Scum”, Feminist Media Studies, 8(1): 17-34.

Watts, C. N. C. M.; Liamputtong, P., and McMichael, C. (2015) Early Motherhood: a Qualitative Study Exploring the Experiences of African Australian Teenage Mothers in Greater Melbourne, Australia,BMC Public Health,15:873.

http://bmcpublichealth.biomedcentral.com/articles/10.1186/s12889-015-2215-2

Wilson, H. and Huntington, A. (2005) Deviant (M)others: The Construction of Teenagers in Contemporary Discourse, Journal of Social Policy, 35(1): 59-76.

Yardley, E. (2008) Teenage Mothers' Experiences of Stigma, Journal of Youth Studies, 11(6): 671-684. 